\title{
Fixed-Dose Combination Antidiabetic Therapy: Real-World Factors Associated with Prescribing Choices and Relationship with Patient Satisfaction and Compliance
}

\author{
Mike Benford · Gary Milligan · James Pike · Peter Anderson · James Piercy · Steve Fermer
}

To view enhanced content go to www.advancesintherapy.com

Received: November 25, 2011 / Published online: January 12, 2012

(C) The Author(s) 2012. This article is published with open access at Springerlink.com

\section{ABSTRACT}

Introduction: Compliance with antidiabetic therapy has the potential to impact on the risk for complications by an effect on glycemic control. Fixed-dose combinations (FDCs) offer a simplified dosing regimen that may improve patient compliance. We undertook a retrospective database analysis to understand the real-world association between FDCs, treatment practices, glycated hemoglobin $\left(\mathrm{HbA}_{1 \mathrm{c}}\right)$ levels, and patient perspectives in type 2 diabetes. Methods: Data were drawn from the Adelphi Diabetes Disease Specific Programme (DSP), a multicenter, patient recordbased market research study of primary care

Mike Benford $(\bowtie) \cdot$ Gary Milligan · James Pike • Peter Anderson · James Piercy · Steve Fermer Adelphi Real World, Adelphi Mill, Bollington, UK. Email: mike.benford@adelphigroup.com

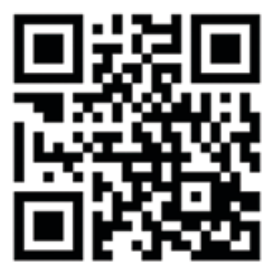

Enhanced content for Advances in Therapy articles is available on the journal web site: www.advancesintherapy.com physicians and diabetologists/endocrinologists in Europe. The study is based on physician interviews, completion of detailed patient record forms by physicians, and a self-completion questionnaire by patients. Regression analyses were used to identify factors associated with (1) physician-reported dipeptidyl peptidase-4 inhibitor (DPP-4)/metformin FDC prescribing in dual or triple therapy regimens; (2) $\mathrm{HbA}_{1 \mathrm{c}}$ of patients prescribed a DPP-4 FDC alone versus free-form DPP-4 plus metformin dual therapy regimens; and (3) differences between patients prescribed any oral antidiabetic therapy (OAD) FDC therapy (alone or in combination with one other $\mathrm{OAD}$ ) versus those prescribed dual or triple OAD free-form combination therapy. Results: Physician-reported data were available for 5891 patients (mean age 61.5 years, $43 \%$ female, mean duration since diagnosis 5.7 years). Factors associated with DPP-4 FDC usage included physicians' reason for choice being "improves patient compliance." The relative mean $\% \mathrm{HbA}_{1 \mathrm{c}}$ level associated with being on a DPP-4 FDC rather than free-form independent of the physician perception of patient compliance was 0.25 lower (CI -0.40 to -0.09 ). When physician-perceived patient compliance was described as "fairly compliant" rather than "poorly compliant" 
or "not at all compliant," the relative mean \% $\mathrm{HbA}_{1 \mathrm{c}}$ level was 0.42 lower (CI -0.67 to -0.18 ). Similarly, being perceived as "fully compliant" rather than "fairly compliant" was associated with a relative mean $\% \mathrm{HbA}_{1 \mathrm{c}}$ level that was 0.17 lower (CI -0.31 to -0.02 ). A significant predictor for the current regimen being any FDC (alone or in combination with one other OAD) regimen was patients' satisfaction with treatment (odds ratio $1.32 ; 95 \%$ CI 1.10 to $1.58 ; P=0.003$ ). Conclusions: These results suggest that DPP-4 FDC prescribing is considered to be a positive prescribing choice to improve compliance and that choice is associated with improved glycemic control. From the patient's perspective, the decision to prescribe an FDC is associated with improved satisfaction with treatment.

Keywords: compliance; dipeptidyl peptidase-4 inhibitors; real-world; satisfaction; simplified dosage regimen; type 2 diabetes

\section{INTRODUCTION}

There are currently more than 346 million individuals worldwide living with a diagnosis of diabetes, $90 \%$ of whom are diagnosed with type 2 diabetes mellitus (T2D). ${ }^{1}$ By 2025 this figure is expected to have increased to 380 million individuals. ${ }^{2}$ In Europe, the prevalence of T2D continues to rise. ${ }^{3}$ Diabetes is a chronic, progressive disease that imposes a considerable physical, social, and emotional burden on individuals. It is associated with reduced life expectancy, significant morbidity due to specific diabetes-related microvascular complications, and an increased risk of macrovascular complications (ischemic heart disease, stroke, and peripheral vascular disease)..$^{3-5}$ Diabetes is also associated with a considerable economic burden, mainly due to the cost of managing long-term complications of the disease. ${ }^{6,7}$
As there is currently no known cure for diabetes, management strategies aim to maintain good glycemic control and minimize the known risk factors for complications of the disease, including both microvascular and macrovascular complications. ${ }^{8}$ However, despite the availability of effective antidiabetic medications, many patients with T2D do not achieve recommended targets for glycemic control. ${ }^{9-12}$ For the majority of individuals this means an ongoing process of treatment intensification, alongside diet and exercise, in an effort to maintain glycemic control using oral antidiabetic medications (metformin, sulfonylureas, thiazolidinediones, and dipeptidyl peptidase-4 [DPP-4] inhibitors) as monotherapy, dual or triple combination regimens, and eventually injectable glucagonlike peptide (GLP-1) agonists or insulinreplacement therapy. ${ }^{8,13,14}$

One factor that has been proposed as a potential factor in the failure to reach and maintain clinical targets among patients with T2D is failure to comply with or adhere or concord to their prescribed antidiabetic regimen. ${ }^{15-18}$ Compliance has been defined as the extent to which a patient acts in accordance with the physician's advice. ${ }^{19}$ The term adherence is often used synonymously with the term compliance and refers to the extent to which a patient acts in accordance with the recommendations agreed with the physician. Concordance implies the patient understands the recommendations..$^{19}$ In the current analysis, the authors have studied compliance with medication as observed by the physician. Satisfaction with treatment may be associated with a patient's willingness or capacity to adhere to their prescribed medication regimen. ${ }^{20}$ Indeed, recent guidelines recognize the need to take into account the willingness of patients to follow and engage positively with their prescribed medication. $^{21}$ 
Improved patient compliance has been associated with improved glycemic control. ${ }^{22}$ Thus steps to improve compliance may have long-term benefits for patients. Compliance with medication in chronic diseases such as diabetes is a complex, multifactorial issue, but the complexity of the medication regimen in terms of pill burden and dosing frequency may impact on a patient's willingness to comply with their prescribed therapy. Moreover, simplification of the medication regimen is well established as a method to improve patient compliance. ${ }^{23}$ A retrospective cohort study among patients with T2D suggested that a single-tablet treatment regimen was associated with better adherence to antidiabetic therapy than one involving multiple tablets. ${ }^{24}$ Thus, regimen simplicity may be a relevant factor when considering the needs of individual patients. For patients requiring combination noninsulin antidiabetic therapy a number of fixed dose combinations (FDCs), including DPP-4 FDCs, are now available that are simpler than regimens that require the patient to take two or more pills several times each day. Real-world research is one method that can help us to understand and identify patients who might benefit most from these new regimens.

There is currently a paucity of data on the real-world impact of the new noninsulin antidiabetic FDCs in relation to patient satisfaction and compliance with therapy. Market research data, such as presented in this article, provides valuable insights into real-world current treatment practices outside the clinical trial setting and the perceived place of new medication regimens in the current noninsulin antidiabetic medication armamentarium. Specifically, the analyses presented here were carried out to better understand the association between FDCs and trends in treatment practices and achieved $\mathrm{HbA}_{1 \mathrm{c}}$ levels in $\mathrm{T} 2 \mathrm{D}$, physician behavior, and patient behavior, both as observed by physicians and reported directly by patients. Understanding patient needs as determined by physicians and the patients themselves is of considerable value to physicians in selecting the most appropriate treatment for individual patients.

\section{MATERIALS AND METHODS}

\section{Study Design}

Data were drawn from the Adelphi Diabetes Disease Specific Programme (DSP), ${ }^{25}$ a large, multinational study that captures a crosssection of robust, real-world data. The DSP is a multi-sponsor survey, conducted under market research guidelines. These data accurately reflect current clinical practice regardless of current national or international clinical guidelines, current symptom prevalence and severity, and physician and patient perception of their health state and its impact on their daily and working life. It collects only information available to the physician/patient at the time of consultation.

The DSP is a patient record-based study of primary care physicians (PCPs) and diabetologists/endocrinologists in France, Germany, Italy, Spain, and the UK of $>4000$ patients. These physicians contributed to the study on a volunteer basis and received payment for their participation. This study was undertaken between October 1, 2009 and March 31, 2010 and is based on physician interviews, completion of detailed patient record forms by physicians, and a self-completion questionnaire by patients. The data collected using this method include subjective, objective, and clinical information about individual patients, their disease and their treatment. The DSP is not run to test any specific hypotheses, and it is not set up to demonstrate cause and effect (as a prospective longitudinal piece of research would). 
The study was performed according to the European Pharmaceutical Market Research Association guidelines ${ }^{26}$ and in full accordance with the US Health Insurance Portability and Accountability Act 1996. While ethical approval is not obtained from local authorities, each patient provided consent for de-identified and aggregated reporting of research findings as required by the guidelines. The data are collected by local fieldwork partners and fully de-identified prior to receipt by Adelphi. The data collected in DSP are not audited externally for data quality.

\section{Physician Eligibility}

To be eligible to participate in the study, PCPs had to have been qualified for $\geq 2$ years and for $\leq 33$ years, to manage $>6$ patients each month at risk of developing T2D and to be managing $>2$ patients each month with a diagnosis of type 1 diabetes (T1D). In addition, they were required to manage $>25$ patients each month with a diagnosis of T2D who were prescribed noninsulin antidiabetic agents with or without insulin. Eligible diabetologists/endocrinologists had to have been qualified for $\geq 2$ years and $\leq 33$ years, to manage $>10$ patients with a diagnosis of $\mathrm{T} 1 \mathrm{D}$ and $\geq 50$ patients with $\mathrm{T} 2 \mathrm{D}$ who were prescribed noninsulin antidiabetic agents with or without insulin.

\section{Patient Eligibility}

Each participating physician completed a detailed patient record form (PRF) for the next six (PCPs) or nine (diabetologists/ endocrinologists) patients who consulted them and who were diagnosed with T2D and were receiving a noninsulin antidiabetic agent with or without insulin during the study period. Participating physicians were also asked to invite all consecutive patients for whom they completed a PRF to complete a patient selfcompletion questionnaire (PSC). As stated above each patient provided consent for de-identified and aggregated reporting of research findings.

\section{Data Collection}

\section{Physician Interviews}

Following an initial screening call, physicians who agreed to participate in the study underwent a 1-hour face-to-face interview. During the interview, information was collected about concomitant conditions, lifestyle, and current drug treatment of the patients with diabetes under their care.

\section{PRFs (Physician Completed)}

Each participating physician completed a detailed PRF for the next six (PCPs) or nine (diabetologists/endocrinologists) eligible patients. This sample is qualified as a "random sample" in this paper because the physicians providing the information had no control over which of the eligible patients in their care presented in their clinic during the data collection period. All responses were anonymized to preserve patient confidentiality.

Physicians provided information from patient records on patient demographics; diabetes history and diagnosis; comorbidities; type of tests performed (and any available results); blood glucose targets and monitoring; lifestyle involvement and engagement with disease; current treatments and reasons for choice; weight management; physician perception of patient compliance (as a single question describing the patient as either "not compliant at all," "poorly compliant," "fairly compliant," or "fully compliant"); hypoglycemic episodes; and healthcare resource utilization including hospitalizations and physician consultations. 
All physicians were asked to provide up to three additional retrospective PRFs for patients receiving recently launched noninsulin antidiabetic agents (including, but not exclusively, DPP-4 agents). This was described as the "over-sample." These patients were not required to be attending for consultation and were not requested to complete a PSC. The oversample records were maintained separately from the prospectively collected random sample. The over-sample was utilized to improve our understanding of patients prescribed recently introduced antidiabetic agents, including FDCs, by securing additional retrospective records for these patients.

\section{Patient PSC Questionnaire}

Using the PSC, information was gathered from the patients' perspective about their disease (blood sugar control, impact on lifestyle, and information sources), treatment and satisfaction with treatment (Diabetes Treatment Satisfaction Questionnaire [DTSQ]), ${ }^{27}$ hypoglycemic events, general health (Euro-QoL-5 Dimensions questionnaire), and the impact of the disease on their ability to work.

Physicians were asked to ensure that all patients from the "random sample" group were given the opportunity to complete the questionnaires in private and to provide patients with an envelope in which to place their completed form and to seal the envelope before returning it to the physician. All responses were anonymized to maintain patient confidentiality.

\section{Study Population}

As noted, DSP data are derived from physicianand patient-completed record forms. Not all physicians and patients answered all the questions on the PRF and PSC, respectively. Consequently, the respondent population size may differ for individual questions and thus for certain analyses. The population size (or base) is given for each individual analysis where appropriate and indicates the number of respondents (physician or patient) who provided responses relevant to that analysis.

\section{Study Questions and Statistical Analyses}

Three separate analyses were undertaken on three separate populations. Analysis 1 studied physician reported data on patients prescribed DPP-4-FDC or DPP-4 free-form therapy on dual or triple therapy regimens $(n=696)$. Analysis 2 studied physician-reported data on patients prescribed dual DPP-4-FDC or DPP-4 free-form therapy on dual therapy regimens $(n=533)$. Analysis 3 studied patient-reported data on patients prescribed any OAD FDC therapy either alone or in combination with one other OAD compared with those prescribed OAD free-form combination therapy $(n=562)$.

\section{Analysis 1. What are the Physician-Related Factors Associated with Prescription of a DPP-4 FDC versus DPP-4 Free-Form Therapy?}

This question was addressed by using matched and combined data from the total patient sample (random sample + over-sample) drawing on information from the physician interview and the PRF. Responses were eligible for inclusion in this analysis if they related to patients receiving dual or triple (or more) agent therapy, without insulin, who were receiving a DPP-4 FDC or free-form combination (that was dose compatible with a DPP-4 FDC) for at least 12 weeks. This was the only stipulation for treatment duration $(n=696)$. A logistic regression analysis was conducted to identify those factors associated with use of a DPP-4 FDC or not. The analysis included the following variables attitudinal responses to 
questions relating to frequency of FDC use and their utility for patients with poor compliance with their prescribed antidiabetic medication regimen, physician satisfaction with blood glucose control, and perceived patient compliance, as well as patient characteristics including age, gender, body mass index (BMI), time since diagnosis, and current comorbidities.

Those variables that showed a significant association with DPP-4 FDC prescription were combined for a single regression analysis. Wald testing was used to evaluate the joint significance of a range of potential covariates. Insignificant variables were then removed from the regression model.

\section{Analysis 2. Is there an Association Between DPP-4 FDC Use, Perceived Level of Compliance, and $\mathrm{Hb}_{1 c}$ Level?}

The second research question used data from the total patient sample (random sample + over-sample) drawing on data recorded in the PRFs for patients receiving dual therapy only $(n=533)$. Responses were eligible for inclusion in this analysis if they related to patients receiving dual therapy, without insulin, who were receiving a DPP-4 FDC or free-form combination therapy (that was dose compatible with a DPP-4 FDC) for at least 12 weeks. This analysis compared $\mathrm{HbA}_{1 \mathrm{c}}$ levels at the last testing (last $\mathrm{HbA}_{1 \mathrm{c}}$ test taken within the last 12 months) between patients prescribed a DPP-4 FDC for at least 12 weeks and those prescribed a dosecompatible DPP-4 free-form combination. An ordinary least squares (linear) regression analysis (OLS) was conducted using Wald testing to evaluate the joint significance of covariates. Insignificant variables were then removed from the regression. Covariates included patient age, gender, BMI, time since diagnosis, prescription of FDC or free-form therapy, patient compliance (physician perception), time spent on regimen (log transformed data). The exact timing of the $\mathrm{HbA}_{1 \mathrm{c}}$ test in relation to the prescription of the DPP-4 FDC or DPP-4 free-form combination was not collected. Physicians completed one of three tick box responses (test conducted in the last 3 months, test conducted at some time in the period between 3 months and 6 months or test conducted in the last 6-12 months). However, the populations in the DPP-4 free form group and the population in the DPP-4 FDC group did not differ in their responses to the tick boxes. Therefore, while the information available relating to timing of the $\mathrm{HbA}_{1 \mathrm{c}}$ test is a limitation of the current analyses, the limitation applies equally to both groups of patients.

\section{Analysis 3. Are There Differences Between Patients Prescribed any OAD FDC Therapy (Alone or in Combination with One Other $O A D)$ Compared with Those Prescribed OAD Free-Form Combination Therapy?}

This question was addressed by using data recorded in the PSCs and included patients from the random sample only (no PSCs were available for patients included in the oversample). Consequently, the research question examined prescription of any OAD FDC (alone or in combination with one other OAD) versus OAD free-form combination prescribing as the cohort of patients who received DPP-4 agents and also provided a PSC was regarded as too small for meaningful comparisons to be made. Responses relating to patients receiving OADs alone who were not receiving insulin or other injectable antidiabetic agents were eligible for inclusion in this analysis.

Due to nature of the data, it was important to ensure the results were independent of age, gender, BMI, and the time since the patient was diagnosed with diabetes; therefore, a multivariate approach was used with these as confounding factors. Two sets of logistic regression analyses 
were conducted including DTSQ covariates and other relevant covariates from the PSCs as well as the aforementioned confounders. The dependent variable was prescription of an FDC (alone or in addition to one OAD) versus OAD free-form combination therapy. To account for the large number of possible covariates, a variable reduction method was employed using a step-wise iterative approach that allowed sequential exclusion of variables with the largest $P$-value until only significant variables remained. Covariates included responses to the DTSQ, patient recollection of factors such as sources of diabetes information, feelings about current blood sugar control, lifestyle adaptations, and the perceived importance of a range of potential benefits of prescribed diabetes treatments.

\section{RESULTS}

A total of 641 physicians took part in the study (384 of whom were PCPs and 257 were specialists) and provided data for a total of 5891 patients (Table 1). For the 4354 patients included in the random sample, 2179 were receiving care from a PCP and 2175 were receiving care from a diabetologist/ endocrinologist. The demographics and disease and treatment characteristics of the study population are summarized in Table 2 .

Table 1. Patient populations by country included in the Adelphi Diabetes Disease Specific Programme (from which the eligible populations for the three analyses were drawn).

\begin{tabular}{lccc}
\hline Country & $\begin{array}{c}\text { Random } \\
\text { sample }\end{array}$ & $\begin{array}{c}\text { Over- } \\
\text { sample }\end{array}$ & $\begin{array}{c}\text { Total } \\
\text { sample }\end{array}$ \\
\hline France & 818 & 295 & 1113 \\
Germany & 900 & 371 & 1271 \\
Italy & 889 & 177 & 1066 \\
Spain & 850 & 322 & 1172 \\
UK & 897 & 372 & 1269 \\
\hline Total & 4354 & 1537 & 5891 \\
\hline
\end{tabular}

Analysis 1. What are the Physician-Related Factors Associated with Prescription of a DPP-4 FDC versus DPP-4 Free-Form Therapy?

This analysis was carried out using physicianreported data from the physician interviews and the PRFs available for the random sample as well as the over-sample. A total of 696 patients out of the population of 1834 DPP-4 users (see Table 2) met the inclusion criteria for this analysis and had received a prescription for a DPP-4 either as an FDC $(n=482)$ or as a free-form combination that was dose compatible with a DPP-4 FDC $(n=214)$ on dual or triple therapy regimens, were receiving therapy for at least 12 weeks, were not receiving an insulin, and had a complete dataset for the variables included in the regression analyses. The demographics and treatment profile of these patients is shown in the univariate analysis in Table 3 . The univariate analysis was used only to define the population for a logistic regression because the univariate analysis does not account for confounders; therefore, no conclusions regarding associations can be drawn from this analysis. It is necessary to correct for these confounders by using the logistic regression analysis method.

The logistic regression analysis identified eight variables as being significantly associated with prescription of a DPP-4 FDC rather than a DPP-4 free-form combination (Table 4). Three variables were associated with less likely to have been prescribed a DPP-4 FDC versus a DPP-4 free-form combination: most recent $\mathrm{HbA}_{1 \mathrm{c}}$ level elevated (physicians were asked to record the most recent $\mathrm{HbA}_{1 \mathrm{c}}$ test result for each patient); "once daily dosing" as a reason for treatment choice; "cost-effective" as a reason for treatment choice. The association between more recent $\mathrm{HbA}_{1 \mathrm{c}}$ level and the proportion of patients prescribed a DPP-4 FDC rather than a free-form DPP-4 is illustrated in Figure 1. 
Table 2. Type 2 diabetes patients (on noninsulin antidiabetics $+/$ - insulin): demographics and current treatments included in the Adelphi Diabetes Disease Specific Programme (from which the eligible populations for the three analyses were drawn).

\begin{tabular}{|c|c|c|c|}
\hline Characteristic & $\begin{array}{l}\text { Random sample } \\
\qquad(n=4354)\end{array}$ & $\begin{array}{c}\text { Over-sample } \\
(n=1537)\end{array}$ & $\begin{array}{c}\text { Total sample } \\
\qquad(n=5891)\end{array}$ \\
\hline Age, mean $( \pm S D)$ & $61.9(11.6)$ & $60.2(10.7)$ & $61.5(11.4)$ \\
\hline Female $(\%)$ & 44 & 40 & 43 \\
\hline Time since diagnosis, mean years $( \pm S D)$ & $5.9(5.8)$ & $5.3(4.5)$ & $5.7(5.5)$ \\
\hline $\mathrm{BMI}$, mean $\mathrm{kg} / \mathrm{m}^{2}( \pm \mathrm{SD})$ & $29.1(5.2)$ & $29.4(5.4)$ & $29.2(5.3)$ \\
\hline Noninsulin OAD (including FDC/GLP-1), $n(\%)$ & $4354(100)$ & $1537(100)$ & $5891(100)$ \\
\hline Biguanides & $3168(73)$ & $763(50)$ & $3931(67)$ \\
\hline SU & $1409(32)$ & $348(23)$ & $1757(30)$ \\
\hline $\mathrm{TZD}$ & $356(8)$ & $77(5)$ & $433(7)$ \\
\hline Prandial glucose regulators & $279(6)$ & $32(2)$ & $311(5)$ \\
\hline GLP-1 agonist & $155(4)$ & $120(8)$ & $275(5)$ \\
\hline DPP-4 inhibitor* & $313(7)$ & $812(53)$ & $1125(19)$ \\
\hline Metformin/DPP-4 inhibitor combination* & $233(5)$ & $481(31)$ & $714(12)$ \\
\hline Metformin/TZD combination & $150(3)$ & $18(1)$ & $168(3)$ \\
\hline Metformin/SU combination & $69(2)$ & $2(<1)$ & $71(1)$ \\
\hline Other OAD $†$ & $112(3)$ & $5(<1)$ & $117(2)$ \\
\hline Insulin, $n(\%)$ & $681(16)$ & $51(3)$ & $732(12)$ \\
\hline Very long acting insulin analogs & $470(11)$ & $40(3)$ & $510(9)$ \\
\hline Biphasic insulin/mixtures & $145(3)$ & $4(<1)$ & $149(3)$ \\
\hline Very rapid acting insulin & $141(3)$ & $9(1)$ & $150(3)$ \\
\hline Intermediate acting insulin & $48(1)$ & $3(<1)$ & $51(1)$ \\
\hline Other insulin $\neq$ & $35(1)$ & $2(<1)$ & $37(1)$ \\
\hline \multicolumn{4}{|l|}{ DPP-4 overview, $n(\%)^{*}$} \\
\hline (Patients on DPP- 4 free-form or DPP-4 FDC combination $[\mathrm{s}]$ ) & $543(12)$ & $1291(84)$ & $1834(31)$ \\
\hline Patients on free-form DPP- $4(s)^{*}$ & $313(7)$ & $812(53)$ & $1125(19)$ \\
\hline Vildagliptin & $46(1)$ & $193(13)$ & $239(4)$ \\
\hline Sitagliptin & $259(6)$ & $604(39)$ & $863(15)$ \\
\hline Saxagliptin & $8(<1)$ & $15(1)$ & $23(<1)$ \\
\hline Patients on DPP-4 FDC combination $(s)^{*}$ & $233(5)$ & $481(31)$ & $714(12)$ \\
\hline Vildagliptin/metformin & $83(2)$ & $193(13)$ & $276(5)$ \\
\hline Sitagliptin/metformin & $150(3)$ & $288(19)$ & $438(7)$ \\
\hline
\end{tabular}

*Three patients were prescribed a DPP-4 in addition to a DPP-4/metformin FDC.

†Includes alpha glucosidase inhibitors and thiazolidinedione/sulfonylurea FDC.

$\neq$ Includes regular insulin and insulin not further specified.

BMI=body mass index; DPP-4=dipeptidyl peptidase-4 inhibitor; FDC=fixed-dose combination; GLP-1=glucagon-like peptide-1 agonist; $\mathrm{OAD}=$ oral antidiabetic; $\mathrm{SD}=$ standard deviation; $\mathrm{SU}=$ sulfonylurea; $\mathrm{TZD}=$ thiazolidinedione.

Figure 1 is derived from the predicted values from the logistic regression model when the other seven independent variables are set to "average" values. The figure illustrates that the proportion of patients prescribed a DPP-4 FDC declined as most recent $\mathrm{HbA}_{1 \mathrm{c}}$ value increased.

The remaining five variables were associated with more likely to have been prescribed a 
Figure 1. Analysis 1. Relationship between \% $\mathrm{HbA}_{\mathrm{lc}}$ level and the proportion of patients receiving a prescription for DPP-4 FDC versus a DPP-4 free-form combination, derived from the predicted values from the logistic regression model when the other seven independent variables are set to "average" values. DPP-4=dipeptidyl peptidase- 4 inhibitor; FDC=fixed-dose combination; $\mathrm{HbA}_{1 \mathrm{c}}=$ glycated hemoglobin.

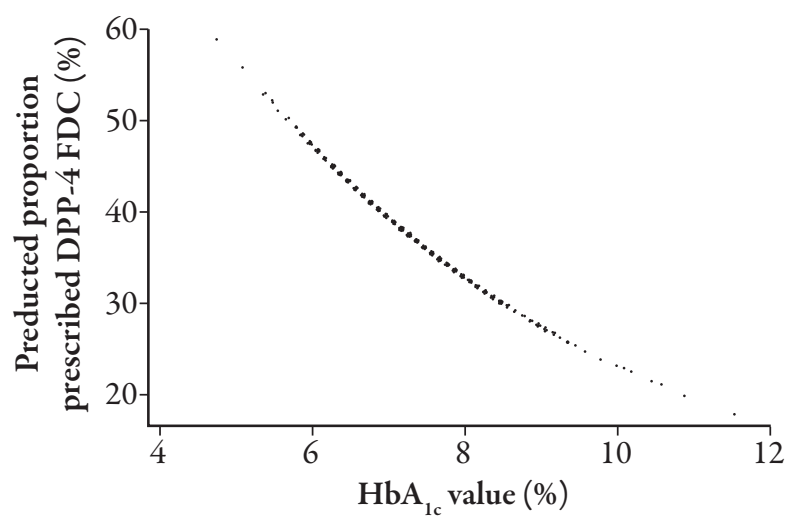

DPP-4 FDC versus a DPP-4 free-form combination. These variables were physician perception of "poor compliance," "fairly compliant," or "fully compliant" versus "not at all compliant" for the patient; "improves compliance," or "covered by insurance" as reasons for physician choice of therapy; physician who indicated that they use FDCs frequently or as a first choice where possible; and physicians who "tend to agree," "agree," or "strongly agree" that they prescribe FDCs to noncompliant patients.

\section{Analysis 2. Is There an Association Between DPP-4 FDC Use, Perceived Level of Compliance, and $\mathrm{HbA}_{1 \mathrm{c}}$ Level?}

This analysis was based on physician's perspectives, drawing on data recorded in the PRFs (random sample and over-sample). To understand differences in $\mathrm{HbA}_{1 \mathrm{c}}$ levels it is important to study dual therapy only with comparable doses. A total of 533 patients met the inclusion criteria for this analysis. Eligible patients had received a prescription for a DPP-4 either as an FDC $(n=383)$ or a freeform combination that was dose compatible with a DPP-4 FDC ( $n=150)$; were receiving dual therapy for at least 12 weeks; were not receiving an insulin; had an $\mathrm{HbA}_{1 \mathrm{c}}$ test result available; and had a complete dataset for the variables included in the regression. The exact timing of the $\mathrm{HbA}_{1 \mathrm{c}}$ test in relation to the prescription of DPP-4 FDC or DPP-4 free-form combination was not collected. This limitation applies equally to both groups of patients.

In Table 5, results are presented using an OLS regression analysis. The results identify variables associated with $\mathrm{HbA}_{1 \mathrm{c}}$ level. Three variables or predictors were identified as being significantly associated with the most recent $\mathrm{HbA}_{1 \mathrm{c}}$ level. Predictors significantly associated with a lower mean $\% \mathrm{HbA}_{1 \mathrm{c}}$ level at the last testing were: prescription of a DPP-4 FDC rather than a free-form combination; physician perception of patients being "fairly compliant" versus "poorly" or "not at all compliant;" physician perception of patients being "fully" versus "fairly compliant." Hence, the relative mean $\% \mathrm{HbA}_{1 \mathrm{c}}$ level associated with being on a DPP-4 FDC rather than freeform, independent of the physician perception of patient compliance, was 0.25 lower (CI -0.40 to -0.09 ). However, if physicianperceived patient compliance was described as "fairly compliant" rather than "poorly compliant" or "not at all compliant," the relative mean \% $\mathrm{HbA}_{1 \mathrm{c}}$ level was 0.42 lower (CI -0.67 to -0.18). Similarly, being perceived as "fully compliant" rather than "fairly compliant" was associated with a relative mean \% $\mathrm{HbA}_{1 \mathrm{c}}$ level that was 0.17 lower (CI -0.31 to -0.02). There were no interactions between these three significant variables and hence the associations between these three variables and the mean $\% \mathrm{HbA}_{1 \mathrm{c}}$ level are additive. 
Table 3. Physician-reported characteristics of patients comparing patients prescribed DPP-4 free-form combination versus a DPP-4 FDC (random sample and over-sample) for patients receiving dual or triple therapy $(n=696$; univariate analysis to confirm population eligible for the logistic regression analysis in Table 4).

\begin{tabular}{|c|c|c|c|c|}
\hline \multicolumn{2}{|l|}{ Characteristic } & \multirow{2}{*}{$\begin{array}{c}\text { DPP-4 free-form } \\
(n=214)\end{array}$} & \multirow{2}{*}{$\begin{array}{c}\text { DPP-4 FDC } \\
(n=482)\end{array}$} & \multirow{2}{*}{$\frac{P \text {-value }}{0.8734^{*}}$} \\
\hline Age (years) & Mean (SD) & & & \\
\hline Female (\%) & $\%$ & 32.7 & 41.7 & $0.0248 \dagger$ \\
\hline Time since diagnosis (years) & Mean (SD) & $5.5(4.4)$ & $4.8(3.9)$ & $0.0615 \dagger$ \\
\hline $\operatorname{BMI}\left(\mathrm{kg} / \mathrm{m}^{2}\right)$ & Mean (SD) & $30.3(5.6)$ & $28.7(4.5)$ & $0.0001^{*}$ \\
\hline Most recent $\mathrm{HbA}_{1 \mathrm{c}}(\%) \neq$ & Mean (SD) & $7.44(0.99)$ & $7.11(0.81)$ & $<0.0001^{*}$ \\
\hline \multirow[t]{4}{*}{ Reasons for treatment (\%) } & Once-daily dosing & 48.1 & 10.4 & $<0.0001 \dagger$ \\
\hline & Improve compliance & 25.7 & 36.3 & $0.0060 \dagger$ \\
\hline & Cost effective & 76.2 & 39.0 & $<0.0001 \dagger$ \\
\hline & Covered by insurance & 36.5 & 59.8 & $<0.0001 \dagger$ \\
\hline \multicolumn{2}{|c|}{$\begin{array}{l}\text { Patients (\%) who physicians described as "poorly compliant," } \\
\text { "fairly compliant," or "fully compliant" vs. "not at all compliant"\$ }\end{array}$} & 95.8 & 99.0 & $0.0060 \dagger$ \\
\hline \multicolumn{2}{|c|}{$\begin{array}{l}\text { Physician (\%) who expressed that they used FDCs frequently } \\
\text { or as first choice\| }\end{array}$} & 38.3 & 63.9 & $<0.0001 \dagger$ \\
\hline \multicolumn{2}{|c|}{$\begin{array}{l}\text { Physicians (\%) who agreed or strongly agreed with the statement } \\
\text { "I tend to use FDCs more in noncompliant patients" }\end{array}$} & 72.4 & 88.2 & $<0.0001 \dagger$ \\
\hline
\end{tabular}

${ }^{*} t$ Test.

†Chi-squared test.

\#The exact timing of the $\mathrm{HbA}_{1 \mathrm{c}}$ test in relation to the prescription of the DPP-4 FDC or DPP-4 free-form combination was not collected. Physicians completed one of three tick box responses (test conducted in the last 3 months, test conducted at some time in the period between 3 and 6 months, or test conducted in the last 6-12 months). However, the populations in the DPP-4 free form group and the population in the DPP-4 FDC group did not differ in their responses to the tick boxes. Therefore, while the information available relating to timing of the $\mathrm{HbA}_{\mathrm{lc}}$ test is a limitation of the current analyses, the limitation applies equally to both groups of patients.

$\S$ Source: patient record form, Section LQ1a - in your experience, how compliant is this patient with their diabetes treatment? Response options: not at all compliant, has poor compliance, fairly compliant, fully compliant.

||Source: physician interview.

Source: physician interview.

$\mathrm{BMI}=$ body mass index; DPP-4=dipeptidyl peptidase-4 inhibitor; FDC=fixed-dose combination; $\mathrm{HbA}_{1 \mathrm{c}}=\mathrm{glycated}$ hemoglobin; $\mathrm{SD}=$ standard deviation.

\section{Analysis 3. Are There Differences Between Patients Prescribed any OAD FDC Therapy (Alone or in Combination with One Other OAD) Compared with Those Prescribed OAD Free-Form Combination Therapy?}

This analysis drew on data recorded in the PSCs, which were available for the random sample only as PSCs were not included in the oversample. Responses relating to 562 patients who were receiving OADs alone and were not receiving insulin or other injectable antidiabetic agents were eligible for inclusion in this analysis. Of these, 155 (28\%) were receiving an FDC alone or in combination with a single OAD, and 407 (72\%) were receiving $\mathrm{OAD}$ free-form combination therapy. Those receiving an FDC had a mean satisfaction with treatment (DTSQ) score of 27.5 ( $\mathrm{SD} \pm 4.69$ ), whilst those on free-form combination therapy had a mean DTSQ score of 26.0 (SD $\pm 5.47 ; P=0.0041)$. 
Table 4. Physician-related factors associated with DPP-4 FDC versus DPP-4 free-form prescription (random sample and over-sample) for patients receiving dual or triple therapy $(n=696$; logistic regression model).

\begin{tabular}{|c|c|c|c|}
\hline Significant variable & Odds ratio & $95 \% \mathrm{CI}$ & $P$-value \\
\hline \multicolumn{4}{|l|}{ Less likely to receive a DPP-4 FDC vs. a DPP- 4 free-form combination } \\
\hline Elevated log-transformed current $\mathrm{HbA}_{1 \mathrm{c}}$ value & 0.09 & $0.01-0.66$ & 0.018 \\
\hline "Once-daily dosing" as reason for treatment choice & 0.09 & $0.05-0.15$ & $<0.0001$ \\
\hline "Cost-effective" as reason for treatment choice & 0.14 & $0.08-0.22$ & $<0.0001$ \\
\hline \multicolumn{4}{|l|}{ More likely to receive a DPP- 4 FDC vs. a DPP- 4 free-form combination } \\
\hline $\begin{array}{l}\text { Patients who physicians described as "poorly compliant," "fairly compliant," } \\
\text { or "fully compliant" vs. "not at all compliant"* }\end{array}$ & 5.21 & $1.30-20.91$ & 0.020 \\
\hline "Improves compliance" as reason for treatment choice & 3.35 & $1.94-5.79$ & $<0.0001$ \\
\hline "Covered by insurance" as reason for treatment choice & 3.77 & $2.35-6.05$ & $<0.0001$ \\
\hline Physicians expressed that they used any FDCs frequently or as a first choice & 2.26 & $1.47-3.46$ & $<0.0001$ \\
\hline $\begin{array}{l}\text { Physician agreed or strongly agreed with the statement "I tend to use FDCs } \\
\text { more in noncompliant patients" } \dagger\end{array}$ & 2.48 & $1.44-4.28$ & 0.001 \\
\hline
\end{tabular}

*Source: patient record form, Section LQ1a - in your experience, how compliant is this patient with their diabetes treatment? Response options: not at all compliant, has poor compliance, fairly compliant, fully compliant.

†Source: physician interview.

$\mathrm{CI}=$ confidence interval; DPP-4=dipeptidyl peptidase- 4 inhibitor; FDC=fixed-dose combination; $\mathrm{HbA}_{1 \mathrm{c}}=\mathrm{glycated}$ hemoglobin.

The logistic regression analyses identified four more patient-focused covariates that were associated with an increased likelihood of receiving an FDC prescription, and four covariates that were associated with an increased likelihood of receiving an OAD freeform combination prescription (Table 6). After correction for confounding factors (age, gender, BMI, and time since the patient was diagnosed with diabetes), a single significant variable remained for the current regimen being any FDC (alone or in combination with one other $\mathrm{OAD}$ ): increased patient satisfaction with their treatment (as indicated by a higher DTSQ score).

Table 5. Variables associated with mean $\% \mathrm{HbA}_{1 \mathrm{c}}$ level among patients receiving dual therapy only, either prescribed a DPP-4 FDC or DPP-4 plus metformin at dosages comparable to those of a DPP-4 FDC (random sample and over-sample $n=533$; OLS regression analysis).

\begin{tabular}{lccc}
\hline $\begin{array}{l}\text { Significant variables associated with the relative } \\
\text { mean \% } \mathrm{HbA}_{1 \mathrm{c}} \text { at most recent test }\end{array}$ & $\begin{array}{c}\text { Difference in mean \% } \\
\mathrm{HbA}_{1 \mathrm{c}} \text { level }\end{array}$ & $\mathbf{9 5 \% \text { CI }}$ & $\boldsymbol{P}$-value \\
\hline $\begin{array}{l}\text { Prescription of a DPP-4 FDC }(n=383) \text { vs. DPP-4 } \\
\text { free-form combination therapy }(n=150)\end{array}$ & -0.25 & -0.40 to -0.09 & 0.002 \\
"Fairly compliant" vs. "poorly compliant" or & & -0.67 to -0.18 & 0.001 \\
"not at all compliant" & -0.42 & -0.31 to -0.02 & 0.026 \\
\hline "Fully compliant" vs. "fairly compliant" & -0.17 & -17
\end{tabular}

BMI=body mass index; $\mathrm{CI}=$ confidence interval; DPP-4=dipeptidyl peptidase-4 inhibitor; FDC=fixed-dose combination; $\mathrm{HbA}_{1 \mathrm{c}}=$ glycated hemoglobin; OLS=ordinary least squares (linear) regression analysis.

Covariates were age, gender, BMI, time since diagnosis, prescription of FDC or free-form therapy, patient compliance, and time spent on regimen. 
Table 6. Covariates significantly associated with any FDC or OAD free-form combination prescribing - patient-reported data (PSC; random sample only $n=562$; logistic regression model).

\begin{tabular}{|c|c|c|c|}
\hline Significant variable & $\begin{array}{l}\text { Odds } \\
\text { ratio }\end{array}$ & $\begin{array}{c}95 \% \mathrm{CI} \\
\text { (Wald test) }\end{array}$ & $\begin{array}{c}P \text {-value } \\
\text { (likelihood ratio test) }\end{array}$ \\
\hline \multicolumn{4}{|c|}{ Less likely to receive OAD FDC vs. OAD free-form combination therapy } \\
\hline $\begin{array}{l}\text { Patients being least satisfied with current treatment being able } \\
\text { to help control their } \mathrm{HbA}_{1 \mathrm{c}} \text { level }\end{array}$ & 0.43 & $0.19-1.00$ & 0.038 \\
\hline BMI & 0.94 & $0.90-0.98$ & 0.006 \\
\hline Nurses indicated as a source of diabetes information & 0.62 & $0.39-0.97$ & 0.032 \\
\hline Age & 0.97 & $0.95-0.998$ & 0.000 \\
\hline \multicolumn{4}{|c|}{ More likely to receive OAD FDC vs. OAD free-form combination therapy } \\
\hline Satisfaction with treatment (DTSQ) & 1.05 & $1.01-1.09$ & 0.011 \\
\hline \multicolumn{4}{|l|}{ Pill size/easy to swallow pills regarded as an important } \\
\hline benefit by patients & 1.17 & $1.02-1.35$ & 0.020 \\
\hline Dissatisfaction with cost of treatment & 2.36 & $1.16-4.78$ & 0.019 \\
\hline No target $\mathrm{HbA}_{1 \mathrm{c}}$ level agreed with doctor & 1.70 & $1.11-2.60$ & 0.015 \\
\hline
\end{tabular}

BMI=body mass index; CI=confidence interval; DTSQ=Diabetes Treatment Satisfaction Questionnaire; FDC=fixed-dose combination; $\mathrm{HbA}_{1 c}=$ glycated hemoglobin; $\mathrm{OAD}=$ oral antidiabetic; $\mathrm{PSC}=$ patient self-completion questionnaire; $\mathrm{SD}=$ standard deviation.

A further analysis of the DTSQ item scores revealed that patients who regarded their current regimen as more convenient (higher score for the question "How convenient have you been finding your treatment to be recently?") were more likely to have been prescribed an FDC regimen than OAD free-form combination therapy (odds ratio 1.32; 95\% CI 1.10 to $1.58 ; P=0.003)$. Those receiving an FDC had a mean score of 4.7 ( $\mathrm{SD} \pm 0.96$, range $0-6)$ for this question, compared with 4.4 ( $\mathrm{SD} \pm 1.14$; $P=0.0055)$ for those on free-form combination therapy. Patients who regarded pill size and ease of swallowing as important benefits of their current regimen were also more likely to be on any FDC. Patients prescribed any FDC regimen were more likely to be dissatisfied with the cost of their treatment and to lack an agreed target $\mathrm{HbA}_{1 \mathrm{c}}$. Dissatisfaction with their current treatment, not being able to control their $\mathrm{HbA}_{1 \mathrm{c}}$, nurses as a source of information about their diabetes (as indicated in response to the question "Which of the following sources have you used for diabetes information?"), older age, and a higher BMI were all significant predictors for the current regimen being OAD free-form combination.

\section{DISCUSSION}

The Adelphi DSPs provide real-world evidence about why disease-management decisions are made, what the decisions are, and the involvement/perspective of the patient. DSP data provide valuable insights into the implications of a disease and its treatment. The relevance and limitations of the Adelphi DSP methodology and cross-sectional design have been published elsewhere. ${ }^{25}$

Data from the Adelphi Diabetes DSP presented here show that a variety of factors appear to be associated with DPP-4 FDC versus DPP-4 free-form combination prescribing. Physician-related factors associated with DPP-4 FDC prescribing decisions were associated with a desire to improve patient compliance. 
Four variables were associated with an increased likelihood of prescribing a DPP-4 FDC rather than a DPP-4 free-form combination (patients described by physicians as having a compliance level of "poor compliance," "fairly compliant," or "fully compliant" versus "not at all compliant;" physicians' reasons for choice being "improves patient compliance" or "covered by health insurance;" physicians who indicated that they used FDCs frequently or as a first choice treatment; physicians who agreed with the statement "I tend to use FDCs more in noncompliant patients").

Predictors significantly associated with a lower $\mathrm{HbA}_{1 \mathrm{c}}$ level at the last testing were prescription of a DPP-4 FDC rather than a free-form combination; physician perception of patients being "fairly compliant" versus "poorly" or "not at all compliant;" physician perception of patients being "fully" versus "fairly compliant." The significant associations of these three variables with the mean $\% \mathrm{HbA}_{1 \mathrm{c}}$ level were additive as there were no interactions between them. Therefore, if a patient is on a DPP-4 FDC rather than free-form DPP-4 and is perceived by the physician to be "fairly compliant," having previously been "poorly compliant" or "not at all compliant," the mean \% $\mathrm{HbA}_{1 \mathrm{c}}$ level would be $0.25+0.42$ giving an overall 0.67 lower level. These results suggest that using DPP-4 FDCs for "not at all compliant" or "poorly compliant" patients would independently facilitate an improvement in mean \% $\mathrm{HbA}_{1 \mathrm{c}}$ level and may assist an improvement to "fairly compliant", which would give rise to the best incremental gain in blood sugar control.

Having corrected for the confounding factors age, gender, BMI, and time since the patient was diagnosed with diabetes, significant predictors for the current regimen being any FDC (alone or in combination with one other OAD) were greater patient satisfaction with their treatment (shown by a higher DTSQ score), patients perception of their current regimen as more convenient (from the DTSQ), and patients regarding pill size and ease of swallowing as important benefits of their current regimen. Patients prescribed any OAD FDC regimen were more likely to be dissatisfied with the cost of their treatment and to lack an agreed target $\mathrm{HbA}_{1 \mathrm{c}}$. Dissatisfaction with their current treatment, not being able to control their $\mathrm{HbA}_{1 \mathrm{c}}$, nurses as a source of information about their diabetes, older age, and a higher BMI were all significant predictors for the current regimen being OAD freeform combination therapy. A previous study has shown that lower levels of treatment satisfaction may be associated with difficulties in taking medications and attending follow-up visits. ${ }^{20}$ Identifying and employing strategies to improve patient satisfaction with treatment may thus prove beneficial in improving patient compliance.

In conclusion, the three analyses undertaken in this retrospective database study suggest that DPP-4 FDC prescribing is considered to be a positive prescribing choice to improve compliance. From the patient's perspective, the decision to prescribe an FDC is associated with improved satisfaction with treatment. These results are consistent with the results of a systematic literature review that suggested that FDC therapy is associated with improved medication taking and treatment satisfaction. ${ }^{28}$ Finally, both better compliance and DPP-4 FDC use are independently associated with a lower $\mathrm{HbA}_{1 \mathrm{c}}$ level, leading to the assumption that better treatment compliance leads to better realworld effectiveness. The associations identified in this study provide support for the hypothesis that prescription of DDP-4 FDCs may indeed lead to improved effectiveness of glucoselowering drugs in the real world. Longitudinal studies are now required to confirm and extend the observations reported here. 


\section{ACKNOWLEDGMENTS}

The authors acknowledge that AstraZeneca and Bristol-Myers Squibb commissioned this retrospective database analysis of the Adelphi Diabetes DSP, proposed the questions to be tested, provided input to the analyses to be performed, reviewed the results, and provided direct input to the manuscript. The authors also acknowledge the editorial support provided by Dr Tracey Lonergan (Adelphi Real World) in the preparation of the manuscript. M.B. is the guarantor for this article, and takes responsibility for the integrity of the work as a whole.

Open Access. This article is distributed under the terms of the Creative Commons Attribution Noncommercial License which permits any noncommercial use, distribution, and reproduction in any medium, provided the original author(s) and source are credited.

\section{REFERENCES}

1. World Health Organization. Diabetes, Fact sheet No 312. August 2011. Available at: http://www. who.int/mediacentre/factsheets/fs312/en/index. html. Accessed September 20, 2011.

2. Van Dieren S, Beulens JW, van der Schouw YT, et al. The global burden of diabetes and its complications: an emerging pandemic. Eur J Cardiovasc Prev Rehabil. 2010;17:S3-8.

3. Danaei G, Finucane MM, Lu Y, et al. National, regional, and global trends in fasting plasma glucose and diabetes prevalence since 1980: systematic analysis of health examination surveys and epidemiological studies with 370 country-years and 2.7 million participants. Lancet. 2011;378:31-40.

4. Fisher L, Mullan JT, Skaff MM, et al. Predicting diabetes distress in patients with Type 2 diabetes: a longitudinal study. Diabet Med. 2009;26:622-627.

5. Fisher L, Mullan JT, Arean P, et al. Diabetes distress but not clinical depression or depressive symptoms is associated with glycemic control in both crosssectional and longitudinal analyses. Diabetes Care. 2010;33:23-28.
6. Perneger TV, Brancati FL, Whelton PK, et al. Endstage renal disease attributable to diabetes mellitus. Ann Intern Med. 1994;121:912-918.

7. Stamler J, Vaccaro O, Neaton JD, et al. Diabetes, other risk factors, and 12 year cardiovascular mortality for men screened in the Multiple Risk Factor Intervention Trial. Diabetes Care. 1993;16:434-444.

8. International Diabetes Federation. IDF Clinical Guidelines Task Force. Global guideline for type 2 diabetes. Brussels: International Diabetes Federation, 2005. Available at: http://www.idf. org/webdata/docs/IDF\%20GGT2D.pdf. Accessed September 20, 2011.

9. Cook MN, Girman CJ, Stein PP, et al. Initial monotherapy with either metformin or sulphonylureas often fails to achieve or maintain current glycaemic goals in patients with type 2 diabetes in UK primary care. Diabet Med. 2007;24:350-358.

10. Huppertz E, Piper L, Klotsche J, et al. Diabetes mellitus in German primary care: quality of glycaemic control and subpopulations not well controlled - results of the DETECT study. Exp Clin Endocrinol Diabetes. 2009;117:6-14.

11. Jenssen TG, Tonstad S, Claudi $T$, et al. The gap between guidelines and practice in the treatment of type 2 diabetes. A nationwide survey in Norway. Diabetes Res Clin Pract. 2008;80:314-320.

12. Ratsep A, Kalda R, Lember M. Meeting targets in type 2 diabetes care contributing to good glycaemic control. A cross-sectional study from a primary care setting in Estonia. Eur J Gen Pract. 2010;16:85-91.

13. Nathan DM, Buse JB, Davidson MB, et al. Medical management of hyperglycemia in type 2 diabetes: a consensus algorithm for the initiation and adjustment of therapy: a consensus statement of the American Diabetes Association and the European Association for the Study of Diabetes. Diabetes Care. 2009;32:193-203.

14. Ryden L, Standl E, Bartnik M, et al. Guidelines on diabetes, pre-diabetes, and cardiovascular diseases: executive summary. The Task Force on Diabetes and Cardiovascular Diseases of the European Society of Cardiology (ESC) and of the European Association for the Study of Diabetes (EASD). Eur Heart J. 2007;28:88-136.

15. Alvarez Guisasola F, Tofe Povedano S, Krishnarajah $\mathrm{G}$, et al. Hypoglycaemic symptoms, treatment satisfaction, adherence and their association with glycaemic goal in patients with type 2 diabetes mellitus: findings from the Real-Life Effectiveness and Care Patterns of Diabetes Management (RECAPDM) study. Diabetes Obes Metab. 2008;10:25-32. 
16. Handelsman Y, Jellinger PS. Overcoming obstacles in risk factor management in type 2 diabetes mellitus. J Clin Hypertens (Greenwich). 2011;13:613-620.

17. Hanko B, Kazmer M, Mumli P, et al. Self-reported medication and lifestyle adherence in Hungarian patients with type 2 diabetes. Pharm World Sci. 2007;29:58-66.

18. Schmittdiel JA, Uratsu CS, Karter AJ, et al. Why don't diabetes patients achieve recommended risk factor targets? Poor adherence versus lack of treatment intensification. J Gen Intern Med. 2008;23:588-594.

19. Horne R, Weinman J, Barber N, et al. Concordance, adherence and compliance in medicine taking. Report for the National Coordinating Centre for NHS Service Delivery and Organisation R\&D (NCCSDO). 2005. Available at: http://www.sdo. nihr.ac.uk/files/project/SDO_ES_08-1412-076_V01. pdf. Accessed November 23, 2011.

20. Biderman A, Noff E, Harris SB, et al. Treatment satisfaction of diabetic patients: what are the contributing factors? Fam Pract. 2009;26:102-108.

21. Benhalima K, Wilmot E, Khunti K, et al. Type 2 diabetes in younger adults: clinical characteristics, diabetes-related complications and management of risk factors. Prim Care Diabetes. 2011;5:57-62.

22. Yurgin NR, Boye KS, Dilla T, et al. Physician and patients management of type 2 diabetes and factors related to glycemic control in Spain. Patient Prefer Adherence. 2008;2:87-95.
23. Vemeire E, Hearnshaw H, Van Royen $\mathrm{P}$, et al. Patient adherence to treatment: three decades of research. A comprehensive review. J Clin Pharm Ther. 2001;26:331-342.

24. Donnan PT, MacDonald TM, Morris AD. Adherence to prescribed oral hypoglycaemic medication in a population of patients with type 2 diabetes: a retrospective cohort study. Diabet Med. 2002;19:279-284.

25. Anderson P, Benford M, Harris N, et al. Realworld physician and patient behaviour across countries: disease-specific programmes - a means to understand. Curr Med Res Opin. 2008;24:30633072 .

26. European Pharmaceutical Market Research, Association Code of Conduct for International, Healthcare Market Research. Available at:www. ephmra.org/professional-standards.aspx. Accessed September 10, 2010.

27. Bradley C. The Diabetes Treatment Satisfaction Questionnaire: DTSQ. In: Bradley C, ed. Handbook of Psychology and Diabetes: a Guide to Psychological Measurement in Diabetes Research and Practice. Chur: Harwood Academic Publishers; 1994:111-132.

28. Hutchins V, Zhang B, Fleurence RL, et al. A systematic review of adherence, treatment satisfaction and costs, in fixed-dose combination regimens in type 2 diabetes. Curr Med Res Opin. 2011;27:1157-1168. 